\title{
Existence of solutions of implicit integral equations via $Z$-contraction
}

\section{PRADip R. PATle and DeEPESh Kumar PATEL}

\begin{abstract}
.
The main focus of this work is to assure that the sum of a compact operator with a $Z$-contraction admits a fixed point. The concept of condensing mapping (in the sense of Hausdorff non-compactness measure) is used to establish the concerned result which generalizes some of the existing state-of-art in the literature. Presented result is used to verify the actuality of solutions of implicit integral equations.
\end{abstract}

Acknowledgements. The first author is thankful to Visvesvaraya National Institute of Technology, Nagpur, India for the fnancial assistance provided during tenure of $\mathrm{PhD}$. The second author is thankful for the support of NBHM, Department of Atomic Energy, Govt. of India (Grant No.-02011/27/2017/R\&D-II/11630).

\section{REFERENCES}

[1] Argoubi, H., Samet, B. and Vetro, C., Nonlinear contractions involving simulation functions in a metric space with a partial order, J. Nonlinear Sci. Appl., 8 (2015), 1082-1094

[2] Banas, J. and Goebel, K., Measure of Noncompactness in Banach Spaces, Lecture Notes in Pure and Appl. Math., 60 Marcel Dekker, Inc., New York, 1980

[3] Barroso, C. S., Krasnoselskii fixed point theorem for weakly continuous maps, Nonlinear Anal., 55 (2003), 25-31

[4] Boriceanu, M., Krasnosel'skii-type theorems for multivalued operators, Fixed Point Theory, 9 (2008), 35-45

[5] Burton, T. A., Integral equations, implicit functions, and fixed points, Proc. Amer. Math. Soc., 124 (1996), 2383-2390

[6] Burton, T. A., A fixed point theorem of Krasnoselskii, Appl. Math. Lett., 11 (1998), 85-88

[7] Burton, T. A. and Kirk, C., A fixed point theorem of Krasnoselskii-Schaefer type, Math. Nachr., 189 (1998), 23-31

[8] Chen, J. and Tang, X., Generalizations of Darbos fixed point theorem via simulation functions with application to functional integral equations, J. Comput. Appl. Math., 296 (2016), 564-575

[9] Darbo, G., Punti uniti in transformazioni a codominio non compatto, Rend. Sem. Math. Univ. Padova, 24 (1955), 84-92

[10] Garcia-Falset, J. and Latrach, K., Krasnoselskii-type fixed-point theorems for weakly sequentially continuous mappings, Bull. London Math. Soc., (2011), doi:10.1112/blms/bdr035

[11] Garcia-Falset, J., Latrach, K., Moreno-Galvez, E. and Taoudi, M.-A., Schaefer-Krasnoselskii fixed point theorems using a ususal measure of weak noncompactness, J. Differentai Equations, 252 (2012), 3436-3452

[12] de-Hierro A. R.-L. and Samet, B., $\varphi$-admissibility results via extended simulation functions, J. Fixed Point Theory Appl., (2016) DOI 10.1007/s11784-016-0385

[13] Khojasteh, F., Shukla, S. and Radenovic, S., A new approach to the study of fixed point theorems via simulation functions, Filomat, 29 (2015), No. 6, 1189-1194

[14] Krasnoselskii, M. A., Some problems of nonlinear analysis, Amer. Math. Society translations, Ser. 2. Vol 10, American Mathematical Society, Providence, R. I., (1958), 345-409

[15] Kryszewski, W. and Mederski, J., Fixed point index for Krasnoselskii-type set valued maps on complete ANR's, Topol. Methods Nonlinear Anal., 28 (2006), No. 2, 335-384

Received: 21.06.2018; In revised form: 23.06.2018; Accepted: 30.06.2018

2010 Mathematics Subject Classification. 54H25, 47H08, 47H10, 37C25.

Key words and phrases. Compact operator, Z-contraction, fixed point, Hausdorff measure of non-compactness, implicit integral equation.

Corresponding author: Deepesh Kumar Patel; deepesh456@gmail.com 
[16] Liu, Y. and Li, Z., Krasnoselskii type fixed point theorems and applications, Proc. Amer. Math. Soc., 136 (2008), No. $4,1213-1220$

[17] Olgun, M., Bicer, O. and Alyildiz, T., A new aspect to Picard operators with simulation functions, Turk. J. Math., 40 (2016), 832-837

[18] Park, S. H., Generalizations of the Krasnoselskii fixed point theorem, Nonlinear Analysis, 67 (2007), 3401-3410

[19] Przeradzki, B., A generalization of Krasnoselskii fixed point theorems for sum of compact and contractible maps with applications, Cent. Eur. J. Math., 10 (2012), 2012-2018

[20] Sadovskii, B. N., Limit-compact and condensing operators, Uspehi Mat. Nauk, 27 (1972), No. 163, 81-146

[21] Smart, D. R., Fixed point theorems, Cambridge Univ. Press, Cambridge, 1980

[22] Wardowski, D., Solving existence problems via F-contractions, Proc. Amer. Math. Soc., (2017), http://dx.doi.org/10.1090/proc/13808

DEPARTMENT OF MATHEMATics

VisvesVARAYA NATIONAL INSTITUTE OF TECHNOLOGY

NAGPUR, 440010 INDIA

E-mail address: pradip.patle12@gmail.com

E-mail address: deepesh456@gmail.com 